(C) This manuscript version is made available under the CC-BY-NC-ND 4.0 license https://creativecommons.org/licenses/by-nc-nd/4.0/

\title{
Disordered lives: Life circumstances and clinical characteristics of very frequent users of emergency departments for primary mental health complaints
}

\author{
Xiangfei Meng ${ }^{\mathrm{a}, \mathrm{b}, *}$, Tracy Mugglic, Marilyn Baetz ${ }^{\mathrm{d}}$, Carl D’Arcy, \\ ${ }^{a}$ Department of Psychiatry, Faculty of Medicine, McGill University, Montreal, Quebec, Canada \\ ${ }^{b}$ Douglas Mental Health University Institute, Montreal, Quebec, Canada \\ ${ }^{c}$ Mental Health and Addition Services, Saskatoon Health Region, Saskatoon, Saskatchewan, Canada \\ ${ }^{d}$ Department of Psychiatry, College of Medicine, University of Saskatchewan, Saskatoon, Saskatchewan, \\ Canada \\ ${ }^{f}$ School of Public Health, University of Saskatchewan, Saskatoon, Saskatchewan, Canada
}

* Corresponding Author. Department of Psychiatry, McGill University, 6875 Boul. LaSalle, Verdun H4H 1R3, Montreal, Canada. Tel:+1 5147616131 ext. 2352. E-mail address: xiangfei.meng@mcgill.ca (X. Meng) 


\begin{abstract}
This study explored the life circumstances and clinical characteristics of frequent users of emergency departments (EDs) presenting with a primary mental health complaint. Patients with 10 or more EDs visits in 2012 with a primary psychiatric diagnosis in a Canadian regional health authority were identified from electronic administrative files. The hospital charts for these patients were thoroughly reviewed for a three-year period, from 2011 to 2013. A retrospective thematic analysis was undertaken. Very frequent users of EDs were generally young to early middle aged, unemployed, living in transient accommodations, having substance abuse diagnoses, and self-referred to EDs for a variety of psychiatric and health symptoms and/or unmet needs. Four themes were identified: 1) substance abuse and associated health and social problems; 2) common mental disorders, which may include suicidality; 3) social and personal stressors with additional common mental disorders and somatic complaints; 4) cognitive impairment with concurrent psychiatric disorders. Traditional mental health services are ineffective in dealing with patients with complex psychiatric and social problems/needs. Efforts should focus on early detection, intervention, reducing mental and behaviour problems, and developing appropriate case management and treatment options. Personalized care models are needed to meet their diverse needs.
\end{abstract}

Keywords Frequent users, psychiatric emergency, unmet needs, complex psychiatric patients 
(c) This manuscript version is made available under the CC-BY-NC-ND 4.0 license https://creativecommons.org/licenses/by-nc-nd/4.0/

\section{Introduction}

There is a rising tide of health service use for mental problems a result of ever more individuals suffering from mental health problems as they face the burden of the restricted instrumental relationships characteristic of modernity, aging and increasing prevalence of chronic diseases, and other socio-economic stressors (Kalucy et al., 2005; Hidaka 2012a, Hidaka et al., 2012b). In contrast, mental health care has shifted from institution-based structure to community-based services, with an increasing focus on the use of combined resources including general practitioners, outpatient and inpatient health facilities (Durbin et al., 2006; Alwan et al., 2008). The provision of long-term mental health care for those with severe and persistent mental health problems has been challenging (Macpherson et al., 2004). There is an increasing gap between needs of mental health patients with complex problems and community resources accessible to these patients. Consequently, these unmet needs result in an increasing number of individuals repeatedly using a considerable number of mental health resources, especially emergency visits (Kalucy et al., 2005).

Cross-sectional studies have demonstrated that frequent visitors at emergency departments (EDs) with multiple unscheduled emergency visits consume a disproportionate proportion of emergency visits (Macpherson et al., 2004; Vandyk et al., 2013; Morlino et al., 2011). Frequent use of EDs is a target for reducing inappropriate health cost and improving patient care. It is suggested that people with frequent visits to EDs are also the major users of other health services (Pines et al., 2011). Studies have shown that those who are young, unemployed, males, living in transient accommodations, and having a psychiatric disorder, are more likely to use EDs (Vandyk et al., 2013). Studies have also consistently shown that substance abuse and other mental health problems are significantly associated with emergency room visits (Fahimi et al., 2015; Brenda et al., 2011; Vu et al., 2015). Active screening for substance abuse and other mental health problems at emergency rooms is recommended. An intervention or a referral for further specialized treatment by a case-management team should be introduced into a general emergency room setting. There are several available care models, including Assertive Community Treatment (ACT), which has been introduced as an effective intervention for people with severe mental illness (Sytema et al., 2007), similarly, Crisis resolution teams, which are more clinical effective than inpatient care for a group of outcomes, and Crisis houses and acute day hospitals with effective treatment outcomes and better user satisfaction (Paton et al., 2016).

However, ittle research has documented the life circumstances and clinical profile of frequent emergency users more longitudinally. This present study aimed to explore the underlying circumstances leading to the very frequent use of EDs for mental health complaints and offer some suggestions for change. A thorough understanding of very frequent emergency users for mental health complaints is essential to offering appropriate health care services, and providing evidence for future direction of mental health care delivery.

We aimed to identify latent reasons for frequent EDs use through a thematic analysis of hospital charts, and to identify the major themes underlying those frequent visits to EDs for mental health complaints. 
(c) This manuscript version is made available under the CC-BY-NC-ND 4.0 license https://creativecommons.org/licenses/by-nc-nd/4.0/

\section{Methods}

\subsection{Context}

Though federally mandated, provincial governments in Canada take the responsibility of most health services delivered within their provinces with the services provided varying somewhat from province to province. These services include almost all hospital and physician services, prescription drug subsidies, a significant proportion of nursing home, and public health (Marchidon and O'Fee, 2007). Saskatchewan is a prairie province in Canada. Saskatoon is a city in central Saskatchewan. It is the largest city in the province with a population of 222,189 in 2011. The Saskatoon Health Region (SHR) is the largest health region in the province, and about $30 \%$ of the province's population resides within the region's geography (http://www.saskatoonhealthregion.ca/about_us/about_us.htm). SHR is an integrated health delivery agency providing a comprehensive range of services and programs including hospital, long-term care, public health, home care, mental health and addiction services, and prenatal and palliative care. Emergency psychiatric services are provided through the Emergency Departments in the three hospital sites in Saskatoon.

\subsection{Study design}

This is a retrospective thematic analysis of frequent users with 10 or more emergency visits to hospitals of the SHR due to primary reason of mental health problems. Electronic administrative data was used to identify patients with 10 or more visits to EDs for the treatment of mental health complaints. This study further undertook a detailed analysis of clinical hospital files for these iodentified clients. The study was approved by the Research Ethics Board, the University of Saskatchewan and the Saskatoon Health Region, Canada.

\subsection{Study population}

A total of 34 patients with 10 or more emergency visits for primary mental health complaints was identified over 1-year period from January $1^{\text {st }}$ to December $31^{\text {st }}, 2012$. Primary diagnosis was assigned by the treating physician, according to the ICD-10 criteria. Health records of all these patients at three sites were thoroughly reviewed for the period from 2011 to 2013. Two authors (XM and CD) independently reviewed all their hospital charts. Information on social-demographical characteristics (age, gender, marital status, accommodation, employment, education, aboriginal status, income source), childhood maltreatment, ever being assaulted, social stressors, emergency visits, hospitalization, medications, physical health, psychiatric diseases, and ever registered in community mental health services system, were systematically extracted from their hospital charts.

\subsection{Thematic analysis}

After a full review of all health records of 34 patients, a thematic analysis was used to explore potential themes or categories for these patients. Figure 1 illustrates the flowchart 
of the process of identifying thematic dimensions and case histories. Two authors (XM and $\mathrm{CD}$ ) independently reviewed and proposed potential dimensions for group discussions. Four thematic dimensions were finalized after group discussions. Inconsistencies in interpretation of themes were resolved through group discussions with all contributing authors.

A quantitative approach was used to describe the basic characteristics of this patient group. All the analyses were completed using SPSS version 21 (SPSS IBM, New York, USA). Proportions were calculated for demographic characteristics, childhood maltreatment, ever being assaulted, social stressors, emergency visits, hospitalization, medications, physical health, psychiatric diseases, and ever registered in regional community mental health services system.

\section{Results}

\subsection{Descriptive findings}

Table 1 presents the detailed information on the 34 patients whose charts were reviewed. There were $22(65 \%)$ males and $12(35 \%)$ females. Their median age was 40, ranging from 16 to 63 . These patients were generally young to early middle age, unemployed, transient, diagnosis of a substance abuse (alcohol abuse), and, self-referring to EDs for psychiatric and physical health symptoms and/or unmet needs (e.g. accommodations), and very frequent users of emergency services. The median of total number of visits in the period from 2011 to 2013 was 43, varying from 19 to 194 . What is clear from these hospital charts is that using the ED was not a single event, but rather a pattern of health care utilization. Possible drug-seeking behavior was noted multiple times as a possible reason for ED visits. A total of seven patients $(20 \%)$ were identified in the charts with drug-seeking behavior over the three years reviewed. There were six patients with an explicit reference to childhood sexual abuse, but for most cases there was no mention of childhood sexual abuse in their charts. The majority of high frequency users also reported a chronic non-infectious health problem (primarily chronic pain: $62 \%$, followed by seizure: $44 \%$, hypertension: $24 \%$, and others), although some had significant infectious disease as well.

\subsection{Findings from thematic analysis}

The detailed information extracted from the hospital charts was used for thematic analysis. Figure 2 summarizes the major findings of thematic analyses. Four themes were identified: 1) Substance abuse, severe alcohol abuse, including patients with withdrawal and seizure secondary to alcohol abuse, drug abuse, and concomitant mood and anxiety disorders, or physical complaints; 2) Common mental disorders, which may also include suicidality; 3) Social and personal stressors with additional common mental disorders and somatic complaints; 4) Cognitive impairment with concurrent psychiatric disorders.

The cases described here are complex and though they are represented as being typical of a specific dominant dimension, they may also contain elements of several dimensions thus underscoring their complexity. 
(c) This manuscript version is made available under the CC-BY-NC-ND 4.0 license https://creativecommons.org/licenses/by-nc-nd/4.0/

\subsection{Cases studies of frequent presenters of emergency care}

The following case histories are offered to illustrate the life circumstances characteristic of frequent users in terms of the four thematic dimensions. Some cases details have been minimized to ensure confidentiality.

\subsubsection{Substance abuse:}

Case \#25 A middle-aged wheelchair male suffers a lot of health problems, both infectious diseases (HIV, Hepatitis C, Staphylococcus aureus (MRSA) positive), and non-infectious diseases (type II diabetes, epilepsy, hip replacement, methicillin-resistant, gun shot wounds, hypertension, chronic alcohol abuse, intravenous drug use, and other health problems). He has been homeless and living on streets. Because of his previous behavior, several temporary shelters have refused him. Noted in his chart was the comment " This patient $(\mathrm{Pt})$ has been in the hospital virtually every night for the last month at different hospitals. Pt presented at emergency departments very frequently, without real symptoms. Pt says his legs are bothering him a little bit, and has an ulcer on his leg that is for sure. Pt has had urinary incontinence. This is basically a matter of choice in this case." In the end the patient is sent home with a final diagnosis of "...minor symptoms of leg swelling, nothing serious."

This patient had a total of 131 visits to emergency department during 2011-2013. Possible drug seeking behavior was noted several times in his hospital charts.

Case\# 6 A middle-aged female has a combination of diseases, including seizure, hepatitis C, hypertension, epilepsy, diabetes, HIV, alcohol abuse, depression, a history of illegal drug use, and suicidal ideation. She is of aboriginal ancestry and had a fairly unstable and traumatic childhood, and had been sexually assaulted in the past. Her husband died. She is on social welfare, and her children were on social assistance.

This patient had a total of 38 visits to emergency during 2011-2013, with most of those visits occurring in 2012 and 2013.

\subsubsection{Common Mental disorders:}

Case\# 29 A middle-aged male is bisexual and in a same sex relationship. He has a Bachelor degree. He lives in a family-supported rented apartment and is on unpaid leave from the Canadian Armed Forces. The patient has been diagnosed with adjustment disorder with mixed mood, narcissistic personality disorder with passive aggressive behavior, depression, obsessive-compulsive disorder, and suicide ideation. There has also been a query about Post Traumatic Stress Disorder (PTSD). It is also noted that the patient is litigious. The patient's physical health problems include hypothyroidism, chronic bladder pain, high cholesterol, and other health problems. The patient has had numerous admissions to EDs, but when there often refuses to speak. He has been frequently brought to EDs by the Emergency Medical Services and police services. He has also called 911 (the universal emergency services telephone number) a number of times. The patient reports trying a number of medications but he has not found them helpful. His parents suffered anxiety and depression. His parents divorced when he was in his late teens. He is currently preoccupied with charges related to his military employment. The patient was hospitalized in 2006 after experiencing depression and suicide ideation. He was hospitalized in 2011 and in 2012 for acute stress and homicidal ideation. In 2013 he was again hospitalized being brought in under the auspices of 
(c) This manuscript version is made available under the CC-BY-NC-ND 4.0 license https://creativecommons.org/licenses/by-nc-nd/4.0/

the Mental Health Act after drenching himself with gasoline.

This patient had a total of 43 visits to the emergency during 2011 - 2013 with most of those visits occurring in 2011 and 2012.

Case \#12 A middle-aged, single male is currently living with his sister and her children. He is a First Nation's member and holds a Masters Degree from a Canadian university and was at the time of this chart review waiting for final admission to a $\mathrm{PhD}$ program at a university in Canada. The patient's primary diagnosis is Bipolar Disorder (for the last 10 years). Alcoholism and schizoaffective disorder are also diagnoses appearing in the patient's chart. The majority of complaints on admission to EDs were of suicide ideation. Nine of the thirty emergency admissions during 2011 to 2013 were for suicide ideation and/or overdose. In five emergency admissions it was noted that the patient was intoxicated. In other emergency admissions the chief complaints were insomnia, depression, dental problems and gastrointestinal bleeding. The patient was hospitalized in 2011 after binge drinking. There is a family history of substance abuse, bipolar disorder, depression and suicide. Patient reports feeling abandoned by family as a child. He was raised in a crowded house on a reserve. The patient is currently estranged from his ex-wife and not allowed to visit his children.

This patient had a total of 30 visits to the emergency during 2011 - 2013 with all off those visits occurring in 2011 and 2012.

Case\# 22 A middle-aged male has a combination of health problems, including cardiovascular disease, heart attacks, numerous assaults on the streets, Type II diabetes, knee replacements, depression, alcohol abuse, alcohol withdrawal, and other health problems. He has been hospitalized for somatic problems. He had a history of childhood abuse and witnessed his grandfather raping his sisters. His father was evicted from home due to alcohol abuse. His major stressors are the fact that his wife left him, no place to study, and being assaulted on the streets.

This patient has a total of 39 visits to the emergency during 2011-2013 with most of those visits (37) occurring in 2011 and 2012. Possible drug seeking behavior is suggested for some these visits.

\subsubsection{Social and personal stressors:}

Case\# 11 A middle-aged female suffers from depression, anxiety, asthma, hypertension, migraine, and other health problems. She had a history of childhood abuse. Her children were sexually abused, but she never dealt with these issues. All her children are in foster care. She had a history of shoplifting. The major reason for her to visit ED was anxiety. She was well known to emergency doctors. She has very poor social skills, and a lot of problems, including separation from her children. It was noted in her hospital chart that "...she is not suicidal, basically is burned out by the circumstances of her life."

This patient had a total of 90 visits to emergency during 2011-13, with the majority of visits (57) occurring in 2013. There are frequent mentions of possible drug seeking behavior for this patient in her hospital chart.

\subsubsection{Cognitive impairment and concurrent psychiatric disorder:}

Case \#17 A young female suffering from complicated physical and psychiatric health problems, including depression, behavioral issues, suicidality, mild cognitive delay, fetal alcohol syndrome, and other gastrointestinal problems. She has been followed as a patient 
since early childhood. She has been physically and emotionally abused, and had multiple admissions to hospital for suicidal thoughts and attempts. She is bisexual, and has numerous incidents of breaking the law. She has multiple stressors, including homeless, unemployment, low education, low cognitive ability, little social support, and poor coping strategies.

This patient had a total of 43 visits to emergency during 2011 - 2013, with the majority of those visits (25) occurring in 2013.

Case \# 27 A middle-aged male has a lot of physical and psychiatric diseases, including hepatitis $\mathrm{C}$, liver cirrhosis, alcoholic dementia, seizure, alcohol abuse, and other health problems. He is deemed unable to make personal/financial decisions. He has no place to stay, and no family support. He has been hospitalized numerous times for alcohol related health problems.

This patient had a total of 69 visits to emergency during 2011 -2013, with the majority of those visits (40) occurring in 2012.

\section{Discussion}

This study describes the life circumstances of frequent EDs users for the treatment of explicit mental health complaints. What has emerged is a profile of individuals who were of young or early middle-age, unemployed, transient, with substance abuse problems (alcohol abuse), and who self-referred to the EDs for a variety of psychiatric and physical health symptoms and unmet needs (e.g. accommodations). This general profile is consistent with prior research (Vandyk et al., 2013; Pines et al., 2011).

The intermediate goal of this study was to better understand the life circumstances of frequent EDs users. It appears those patients can be categorized along four dimensions: 1) substance use/misuse group (alcohol abuse/withdrawal or illicit drug use); 2) mood and anxiety disorders groups; 3 ) personal and social stressors group (with or without mental disorders); and 4) psychiatric diseases and cognitive impairment group. The cases described here, though complex, are illustrative of a specific dimension though they may contain elements of other dimensions as well. Our themes summarize the different domains/dimensions characteristic of frequent users and provide fundamental evidence of their diverse needs.

The substance abuse (especially alcohol abuse) group was the most numerous and dominant one among all these frequent users. Continuing seeking and drinking of alcohol by the affected individuals without consideration of adverse health, social and economic consequences are the major problem with alcohol abuse. It is well known that excessive alcohol consumption increases the risk of mental disorders, e.g. depression, anxiety, psychosis, cognitive function, cardiovascular disease, and other health problems (Tolstrup et al., 2006; O'Keefe et al., 2014). Alcohol abuse is also tangled in relationship breakdown, violence, self-management, and poor parenting. Alcohol abuse is associated with hepatitis $C$ infection and illicit drug use (Srivastava et al., 2008; Teplin et al., 2007). It is estimated that up to $50 \%$ of homeless people suffer from alcohol abuse (Gill et al., 1996). In this study, we found that $53 \%$ of visits were related to alcohol abuse. This finding brings into question the effectiveness of the current modes of treatment for alcohol abuse. It has been consistently found that psychosocial interventions aiming at reducing consumption behavior are effective interventions for the problematic alcohol 
use (Kaner et al., 2007; Poikolainen, 1999). Early detection and intervention change the pattern of alcohol use. Integrated psychosocial intervention programs should also be used in a routine care (Klimas et al., 2013).

It is not uncommon to see comorbidity between depression and anxiety. These disorders are commonly comorbid with other psychiatric disorders and physical diseases, such as cardiovascular diseases, diabetes (Aina and Susman, 2006). People with depression and/or anxiety place a large service demand on the health care system. Suicide attempters are commonly seen to be suffering affective and anxiety disorders, and are significantly associated with substance abuse and intensive care demands (LopezCastroman et al., 2011). In this study, we found a group of frequent EDs users with a diagnosis of depression or anxiety at admission and who had a history of depression, anxiety, or suicidality. Psychotherapeutic approaches are recommended for reducing and preventing depression and anxiety disorders, with an emphasis on cognitive behavior therapy (Clark et al., 2001).

Social environmental stresses and their responses (coping strategies, e.g. alcohol use) are associated with a higher risk of health problems (Cohen et al., 2001; Fishbein et al., 2006; Marsland et al., 2001). Many emergency patients experience physical and mental health problems that are negative consequences of maladaptive behaviors used to cope with a variety of stressors (McQuarrie et al., 1998). Our study found a group of high frequency ED users who not only suffered from common mental disorders, but also had to deal with a lot of personal and social problems, including lack of accommodations, unemployment, family relationships, etc. These problems appear to be a major reason for their emergency department use. Hamm et al. (2010) in their systematic review of crisis interventions in EDs found that the use of specific care model of mental health in pediatric patients reduced hospitalization, recurrent emergency visits, and length of hospital stay. They lived very disordered lives. Considering the burden place on the health care system by this specific group of frequent EDs users, a referral or an intervention emphasizing stress management should be prioritized for these patients. Effective intervention program basedon adaptive coping strategies should also be considered in order to minimize the side effects of stressors.

Notably, we found that a small group of patients suffered both psychiatric disorders and intellectual disability. Patients cannot make their own decisions and were living in group homes or transient. The current services for these patients need to be adjusted towards their needs. More appropriate health service and support should be provided.

Fundamental to solving this problem is the development of comprehensive guide for the treatment and referral of patients presenting in emergency with mental health complaints (Mental Health and Drug and Alcohol Office, 2009)

\subsection{Strengths and limitations}

This study used a thematic analysis to investigate in-depth details of the life circumstances and clinical characteristics of all patients in a health region who were very frequent EDs users for explicit mental health complaints. Our study is limited in so far as the generalizability of our findings may be limited by the specifics of the structure of mental health care system examined. Further research should be continued to explore profiles of heavy EDs users in different geographic locations and in different social 
(c) This manuscript version is made available under the CC-BY-NC-ND 4.0 license https://creativecommons.org/licenses/by-nc-nd/4.0/

milieux. The operationalization of heavy EDs user's definition may impact on the findings.

\subsection{Conclusions}

In this study, we found that very frequent users of EDs were generally young to early middle age, unemployed, living in transient accommodations, with substance abuse diagnoses, and self-referred to EDs for a variety of psychiatric and health symptoms and/or unmet needs. Four thematic dimensions were identified: 1) substance abuse and associated health and social problems; 2) common mental disorders, which may include suicidality; 3) social and personal stressors with additional common mental disorders and somatic complaints; 4) cognitive impairment with concurrent psychiatric disorders.

In general, there is an increasing number of individuals are accessing mental health services and requiring acute care intervention. Whereas, policy driven bed closures and pressure to reduce length of stay on psychiatric units limit hospital admission and the extent of inpatient care. As a result, even individuals with the most complex and severe forms of mental illness live and receive the majority of their care in the community. Navigating the multi-service and decentralized healthcare system required for psychiatric care is difficult for individuals with mental illness given the complex nature of their service needs, and the ongoing organizational changes, and the memory and cognitive symptoms associated with their conditions. Psychological and physical stressors have been found to major drivers of the heavy use of emergency care. Child sexual abuse is correlated with psychopathology and high risk of suicidality (Perez-Fuentes et al., 2013). Violence, alcohol abuse, and mental disorders together are associated with the risk of HIV (Meyer et al., 2011). A recent study on frequent emergency use among released prisoners with HIV demonstrates that the major driver of frequent use of emergency is comorbid medical and psychiatric illness (Meyer et al., 2013). In addition, mental disorders, and child abuse are the major causes of years homeless (Trypuc and Robinson, 2009).

Stable accommodation is critical to maintain stable circumstance. Ku et al. (2010) compared the emergency visits by homeless and non-homeless using the National Hospital Ambulatory Medical Care Survey in the US and found that homeless people were more likely to use ambulance, have no medical insurance coverage and being diagnosed with psychiatric and substance abuse. The Mental Health Commission of Canada (MHCC) launched the "At Home" project to evaluate the effectiveness of the "housing first" approach for people who are homeless and living with mental health issues, where people are provided with a place to live and then offered recovery-oriented services and supports that best meet individual needs

(http://www.mentalhealthcommission.ca/English/initiatives-andprojects/home? routetoken=89cb6cabf12421 e16ffd2eec $7378 \mathrm{c} 12 \mathrm{f} \&$ terminitial $=38$ ).

Studies also have suggested that increasing therapeutic and interpersonal communication in the emergency departments could be very helpful for someone in a psychiatric crisis (Blank et al., 2004; Summers and Happell, 2003). Taylor advised "Just as a warm blanket or pain medicine might be most therapeutic to someone with a medical illness, music to calm, a book to occupy the mind, or a listening and supportive ear may be the most therapeutic intervention to someone in a psychiatric crisis." (Taylor, 2004). 
For those suffering with severe mental disorders, ACT, supported employment, and integrated treatments for dual disorders, especially the first two practices have been considered as cost-effective approaches (Appell et al., 2016). The unified teams of treatment and rehabilitation staff in assertive community treatment offer more costeffective mental health services to severe mental patients (Latimer, 2005).

The following procedures should be recommended in EDs in order to reduce the emergency visits and provide more appropriate/ personalized health services and care to the population.

1) Identify characteristics associated with heavy use of EDs

2) Predict which patients are at risk for becoming or remaining frequent users

3) Flag which patients who are at risk of frequent use of EDs

4) Conduct case analysis for frequent users to explore reasons of heavy use of EDs

5) Develop a professional team designed for the treatment and care of severe mental patients providing better health and social services

6) Implement both EDs based and non-EDs based interventions

7) Based on the above develop a comprehensive reference guide for the treatment of patients presenting in emergency departments with mental health.

Acknowledgements This work was supported by a grant from Saskatchewan Ministry of Health and the Saskatoon Health Region, Canada.

Compliance with ethical standards Ethnical approval was obtained from the University of Saskatchewan Behavioral and Biomedical Research Ethics Boards (\#12-364).

Conflict of interest The authors declare that they have no conflict interest. 
(c) This manuscript version is made available under the CC-BY-NC-ND 4.0 license

https://creativecommons.org/licenses/by-nc-nd/4.0/

\section{References}

Aina, Y., Susman, J.L., 2006. Understanding comorbidity with depression and anxiety disorders. Journal of the American Osteopathic Association 106, S9-14.

Alwan, N.A., Johnstone, P., Zolese, G., 2008. Length of hospitalisation for people with severe mental illness. Cochrane Database Systematic Review (1), CD000384.

Appell, C., Burns, B., Cohen, M., Drake, R., Goldman, H., Gorman, P., Evidence-based practices: shaping mental health services toward recovery. Deparment of Health and Human Services, Substance Abuse and Mental Health Services Administration's Center for Mental Health Services. www.mentalhealthpractices.org (accessed 16.02.12).

Blank, F.S., Keyes, M., Maynard, A.M., Provost, D., Santoro, J.P., 2004. A humane ED seclusion/restraint: legal requirements, a new policy, procedure, "psychiatric advocate" role. Journal of Emergency Nursing 30, 42-46.

Brenda, M.B., Maureen, A.W., Kristin, L.B., Rebecca, M.C., Stephen, T.C., Frederic, C.B., 2011. Substance Use, Depression and Mental Health Functioning in Patients Seeking Acute Medical Care in an Inner-City ED. Journal of Behavioral Health Services \& Research 38: 358-372.

Clark, D.M., Layard, R., Smithies, R., Richards, D.A., Suckling, R., Wright, B., 2009. Improving access to psychological therapy: Initial evaluation of two UK demonstration sites. Behaviour Research and Therapy 47, 910-920.

Cohen, S., Miller, G.E., Rabin, B.S., 2001. Psychological stress and antibody response to immunization: a critical review of the human literature. Psychosom Med 63, 7-18.

Durbin, J., Goering, P., Streiner, D.L., Pink, G., 2006. Does systems integration affect continuity of mental health care? Administration and Policy in Mental Health and Mental Health Services Research 33, 705-717.

Fahimi, J., Aurrecoechea, A., Anderson, E, Herring, A., Alter, H., 2015. Substance abuse and mental health visits among adolescents presenting to US emergency departments. Pediatric Emergency Care 31:331-338.

Fishbein, M.H., Mogren, C., Gleason, T., Stevens, W.R., 2006. Relationship of hepatic steatosis to adipose tissue distribution in pediatric nonalcoholic fatty liver disease. Journal of Pediatric Gastroenterology and Nutrition 42, 83-88.

Gill, B., Meltzer, H., Hinds, K., Petticrew, M., 1996. Psychiatric morbidity among homeless people. OPCS surveys of psychiatric morbidity in Great Britain, Report 7. HMSO, London.

Hamm, M.P., Osmond, M., Curran, J., Scott, S., Ali, S., Hartling, L., Gokiert, R., Cappelli, M., Hnatko, G., Newton, A.S., 2010. A systematic review of crisis interventions used in the emergency department: recommendations for pediatric care and research. Pediatric Emergency Care 26, 952-962.

Hidaka, B.H., 2012a. Depression as a disease of modernity: explanations for increasing prevalence. Journal of Affective Disorders 140, 205-214.

Hidaka, S., Ikejima, C., Kodama, C., Nose, M., Yamashita F, Sasaki M, Kinoshita T, Tanimukai S, Mizukami K, Takahashi H, Kakuma T, Tanaka S, Asada T., 2012b Prevalence of depression and depressive symptoms among older Japanese people: comorbidity of mild cognitive impairment and depression. International Journal of Geriatric Psychiatry 27, 271-279. 
Kalucy, R., Thomas, L., King, D., 2005. Changing demand for mental health services in the emergency department of a public hospital. Australian and New Zealand Journal of Psychiatry 39, 74-80.

Kaner, E.F., Beyer, F., Dickinson, H.O., Pienaar, E., Campbell, F., Schlesinger, C., Heather, N., Saunders, J., Burnand, B., 2007. Effectiveness of brief alcohol interventions in primary care populations. Cochrane Database Systematic Review18, CD004148.

Klimas, J., Field, C.A., Cullen, W., O'Gorman, C.S., Glynn, L.G, Keenan, E., Saunders, J., Bury, G., Dunne, C., 2013. Psychosocial interventions to reduce alcohol consumption in concurrent problem alcohol and illicit drug users: Cochrane Review. Systematic Reviews 2, 3.

Ku, B.S., Scott, K.C., Kertesz, S.G., Pitts, S.R. 2010. Factors associated with use of urban emergency departments by the U.S. homeless population. Public Health Reports 125, 398-405.

Latimer, E., 2005. Economic considerations associated with assertive community treatment and supported employment for people with severe mental illness. Journal of Psychiatry \& Neuroscience 30, 355-359.

Lopez-Castroman, J., Perez-Rodriguez, Mde.L., Jaussent, I., Alegria, A.A., ArtesRodriguez, A., Freed, P., Guillaume S, Jollant F, Leiva-Murillo JM, Malafosse A, Oquendo, M.A., de Prado-Cumplido, M., Saiz-Ruiz, J., Baca-Garcia, E., Courtet, P., European Research Consortium for Suicide (EURECA). 2011. Distinguishing the relevant features of frequent suicide attempters. Journal of Psychiatric Research 45, 619-625.

Macpherson, R., Shepherd, G., Edwards, T., 2004. Supported accommodation for people with severe mental illness: a review. Advances in Psychiatric Treatment 10,180-188.

Marchidon, G.P., O'Fee, K., 2007. Health care in Saskatchewan: an analytical profile. Canadian Plains Research Center and Saskatchewan Institute of Public Policy, Regina.

Marsland, A.L., Cohen, S., Rabin, B.S., Manuck, S.B., 2001. Associations between stress, trait negative affect, acute immune reactivity, and antibody response to hepatitis B injection in healthy young adults. Health Psychology 20, 4-11.

McQuarrie, S.A., Riauka, T., Baum, R.P., Sykes, T.R., Noujaim, A.A., Boniface, G., MacLean, G.D., McEwan, A.J., 1998. The effects of circulating antigen on the pharmacokinetics and radioimmunoscintigraphic properties of $99 \mathrm{~m}$ Tc labelled monoclonal antibodies in cancer patients. Journal of Pharmacy and Pharmaceutical Sciences 1, 115-125.

Meyer, J.P., Springer, S.A., Altice, F.L., 2011. Substance abuse, violence, and HIV in women: a literature review of the syndemic. Journal of Women's Health 20, 991-1006.

Meyer, J.P., Qiu, J., Chen, N.E., Larkin, G.L., Altice, F.L., 2013. Frequent Emergency Department Use among Released Prisoners with HIV: Characterization Including a Novel Multimorbidity Index. Academic Emergency Medicine 20,79-88.

Morlino, M., Calento, A., Schiavone, V., Santone, G., Picardi, A., de Girolamo, G., PROGRES-Acute group, 2011. Use of psychiatric inpatient services by heavy users: findings from a national survey in Italy. European Psychiatry 26, 252-259.

Mental Health and Drug and Alcohol Office, 2009. Mental Health for Emergency Departments - A Reference Guide. Sydney, New South Wales (NSW) Department of Health. 
O'Keefe, J.H., Bhatti, S.K., Bajwa, A., DiNicolantonio, J.J., Lavie, C.J., 2014. Alcohol and cardiovascular health: the dose makes the poison...or the remedy. Mayo Clinic Proceedings 89:382-393.

Paton, F., Wright, K., Ayre, N., Dare, C., Johnson, S., Lloyd-Evans, B., Simpson, A., Webber, M., Meader, N., 2016. Improving outcomes for people in mental health crisis: a rapid synthesis of the evidence for available models of care. Health Technology Assessment 20: 1-162.

Perez-Fuentes, G., Olfson, M., Villegas, L., Morcillo, C., Wang, S., Blanco, C., 2013. Prevalence and correlates of child sexual abuse: a national study. Comprehensive Psychiatry 54,16-27.

Pines, J.M., Asplin, B.R., Kaji, A.H., Lowe, R.A., Magid, D.J., Raven, M., Weber, E.J., Yealy D.M., 2011. Frequent users of emergency department services: gaps in knowledge and a proposed research agenda. Academic Emergency Medicine 18, e6469.

Poikolainen, K., 1999. Effectiveness of brief interventions to reduce alcohol intake in primary health care populations: a meta-analysis. Preventive Medicine 28, 503-509.

Srivastava, A., Kahan, M., Ross, S., 2008. The effect of methadone maintenance treatment on alcohol consumption: a systematic review. Journal of Substance Abuse Treatment 34, 215-223.

Summers, M., Happell, B., 2003. Patient satisfaction with psychiatric services provided by a Melbourne tertiary hospital emergency department. Journal of Psychiatric and Mental Health Nursing 10, 351-357.

Sytema, S., Wunderink, L., Bloemers, W., Roorda, L., Wiersma, D., 2007. Assertive community treatment in the Netherlands: a randomized controlled trial. Acta Psychiatrica Scandinavica. 116:105-112.

Taylor, A., 2004. Rethinking the way we care for psychiatric patients in crisis. Journal of Emergency Nursing 30, 202-203.

Teplin, D., Raz, B., Daiter, J., Varenbut, M., Plater-Zyberk, C., 2007. Screening for alcohol use patterns among methadone maintenance patients. American Journal of Drug and Alcohol Abuse 33, 179-183.

Tolstrup, J., Jensen, M.K., Tjonneland, A., Overvad, K., Mukamal, K.J., Gronbaek, M., 2006.Prospective study of alcohol drinking patterns and coronary heart disease in women and men. BMJ 332, 1244-1248.

Trypuc, B., Robinson, J., 2009. Homeless in Canada: A Funder's primer in understanding the tragedy on Canada's streets. https://www.charityintelligence.ca/images/CiHomeless-in-Canada.pdf (accessed 15.12.12).

Vandyk, A.D., Harrison, M.B., VanDenKerkhof, E.G., Graham, I.D., Ross-White, A., 2013. Frequent emergency department use by individuals seeking mental healthcare: a systematic search and review. Archives of Psychiatric Nursing 27, 171-178.

Vu, F., Daeppen, J.B., Hugli, O., Iglesias, K., Stucki, S., Paroz, S., Canepa Allen, M., Bodenmann, P., 2015. Screening of mental health and substance users in frequent users of a general Swiss emergency department. BMC Emergency Medicine 15:27. 
Table 1 Characteristics of heavy emergency users $(\mathrm{N}=34)$ in 2012

\begin{tabular}{|c|c|c|c|}
\hline Characteristics & Subcategory & $\%$ & $\mathrm{~N}$ \\
\hline \multirow[t]{2}{*}{ Gender } & Male & 65.00 & 22 \\
\hline & Female & 35.00 & 12 \\
\hline \multirow[t]{3}{*}{ Accommodation } & Ever homeless & 50.00 & 17 \\
\hline & Ever transient & 58.82 & 20 \\
\hline & Ever in a group home & 14.71 & 5 \\
\hline \multirow[t]{2}{*}{ Childhood experience } & Sexual abuse & 17.65 & 6 \\
\hline & Physical abuse & 2.94 & 1 \\
\hline$\underline{\text { Ever assaulted }}$ & Ever & 50.00 & 17 \\
\hline \multirow[t]{6}{*}{ Education } & Less than grade 9 & 2.94 & 1 \\
\hline & Grade 9-11 & 38.24 & 13 \\
\hline & Grade 12 & 17.65 & 6 \\
\hline & Some post secondary & 5.88 & 2 \\
\hline & Post secondary & 20.59 & 7 \\
\hline & Unknown & 14.71 & 5 \\
\hline \multirow[t]{7}{*}{ Income source } & Social assistance & 50.00 & 17 \\
\hline & Employed & 14.71 & 5 \\
\hline & Pension & 2.94 & 1 \\
\hline & Disability & 5.88 & 2 \\
\hline & Family & 8.82 & 3 \\
\hline & Other & 5.88 & 2 \\
\hline & Unknown & 11.76 & 4 \\
\hline Ever hospitalized & Ever & 82.35 & 28 \\
\hline \multicolumn{4}{|l|}{$\frac{\text { Addiction \& Mental }}{\text { Health Information }}$} \\
\hline$\frac{\text { Family history of }}{\text { psychiatric diseases }}$ & $\begin{array}{l}\text { Never registered } \\
\text { With }\end{array}$ & $\begin{array}{r}5.88 \\
44.12\end{array}$ & $\begin{array}{l}2 \\
15\end{array}$ \\
\hline \multirow[t]{3}{*}{ Physical health condition } & Chronic (non-infectious) disease & 97.06 & 33 \\
\hline & Infectious liver disease & 23.53 & 8 \\
\hline & AIDS/HIV & 11.76 & 4 \\
\hline \multirow{5}{*}{$\begin{array}{l}\text { Psychological health } \\
\text { condition }\end{array}$} & Depression & 47.06 & 16 \\
\hline & Anxiety & 29.41 & 10 \\
\hline & Alcohol abuse & 52.94 & 18 \\
\hline & Drug abuse & 11.76 & 4 \\
\hline & Psychosis & 5.88 & 2 \\
\hline \multirow[t]{6}{*}{ Major reason for visits } & Alcohol abuse & 52.94 & 18 \\
\hline & Depression & 11.76 & 4 \\
\hline & Anxiety & 26.47 & 9 \\
\hline & Chronic pain & 17.65 & 6 \\
\hline & Somatic problems & 14.71 & 5 \\
\hline & Suicidality & 14.71 & 5 \\
\hline
\end{tabular}


(C) This manuscript version is made available under the CC-BY-NC-ND 4.0 license https://creativecommons.org/licenses/by-nc-nd/4.0/

\begin{tabular}{|c|c|c|}
\hline & Drug seeking & 8.82 \\
\hline Not from Saskatoon & From outside of Saskatoon & 20.59 \\
\hline
\end{tabular}




\section{Step 1: Review individual medical charts}

Author: XM

$$
\text { Author: CD }
$$

\section{Step 2: Extract individual case history}

Author: XM

$$
\text { Author: CD }
$$

Step 3: Identify frequent characteristics

Author: XM

Author: CD

Step 4: Propose major themes for discussion

Group discussions with all authors

Step 5: Develop major themes for this study

Group discussions with all authors Step 6: Finalize major themes for this study

Figure 1 A flowchart of thematic analysis process 
(C) This manuscript version is made available under the CC-BY-NC-ND 4.0 license https://creativecommons.org/licenses/by-nc-nd/4.0/

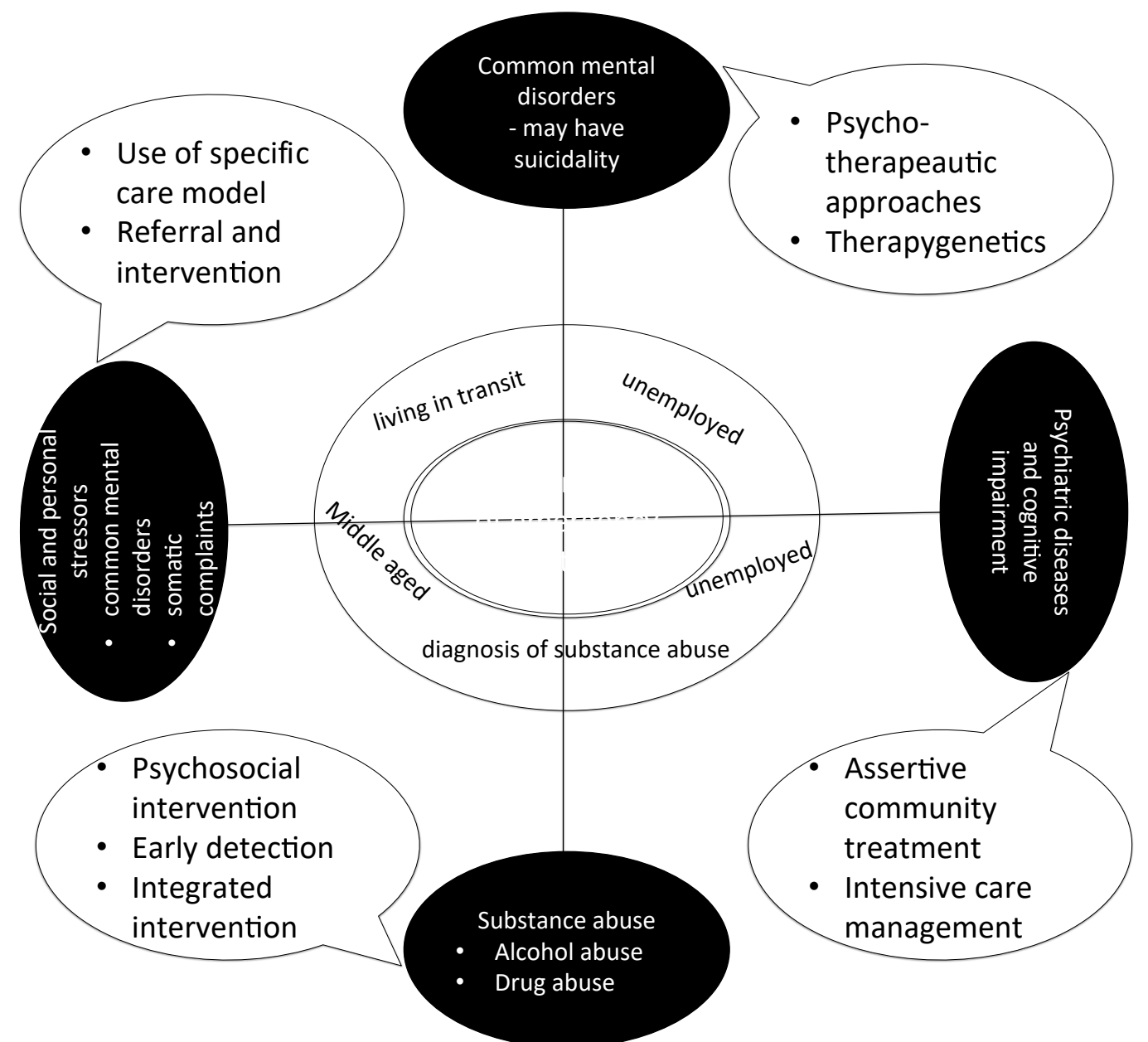

Figure 2 A summary of findings from thematic analyses of heavy emergency users 